(2) OPEN ACCESS

\title{
Distal hereditary motor neuronopathy of the Jerash type is caused by a novel SIGMAR1 C.500A>T missense mutation
}

\author{
Antonis Ververis, ${ }^{1,2}$ Rana Dajani, ${ }^{3}$ Pantelitsa Koutsou, ${ }^{1}$ Ahmad Aloqaily, ${ }^{4}$ \\ Carol Nelson-Williams, ${ }^{5}$ Erin Loring, ${ }^{5}$ Ala Arafat, ${ }^{3}$ Ammar Fayez Mubaidin, ${ }^{6}$ \\ Khalid Horany, ${ }^{6}$ Mai B Bader, ${ }^{7}$ Yaqoub Al-Baho, ${ }^{7}$ Bushra Ali, ${ }^{7}$ Abdurrahman Muhtaseb, ${ }^{8}$ \\ Tyrone DeSpenza Jr, ${ }^{5}$ Abdelkarim A Al-Qudah, ${ }^{7}$ Lefkos T Middleton, ${ }^{9}$ \\ Eleni Zamba-Papanicolaou, ${ }^{2,10}$ Richard Lifton, ${ }^{5}$ Kyproula Christodoulou

\begin{abstract}
- Additional material is published online only. To view please visit the journal online (http://dx.doi.org/10.1136/ jmedgenet-2019-106108).

For numbered affiliations see end of article.
\end{abstract}

\section{Correspondence to} Professor Kyproula Christodoulou, Neurogenetics Department, The Cyprus Institute of Neurology and Genetics, Nicosia 2371, Cyprus; roula@cing.ac.cy

$\mathrm{AV}$ and $\mathrm{RD}$ contributed equally.

Received 25 February 2019 Revised 6 August 2019 Accepted 10 August 2019 Published Online First 11 September 2019

\begin{abstract}
Background Distal hereditary motor neuronopathies (dHMN) are a group of genetic disorders characterised by motor neuron degeneration leading to muscle weakness that are caused by mutations in various genes. HMNJ is a distinct form of the disease that has been identified in patients from the Jerash region of Jordan. Our aim was to identify and characterise the genetic cause of HMNJ. Methods We used whole exome and Sanger sequencing to identify a novel genetic variant associated with the disease and then carried out immunoblot, immunofluorescence and apoptosis assays to extract functional data and clarify the effect of this novel SIGMAR 1 mutation. Physical and neurological examinations were performed on selected patients and unaffected individuals in order to re-evaluate clinical status of patients 20 years after the initial description of HMNJ as well as to evaluate new and previously undescribed patients with HMNJ.
\end{abstract}

Results A homozygous missense mutation (c.500A $>T_{\text {, }}$ $\mathrm{N167I)}$ in exon 4 of the SIGMAR1 gene was identified, cosegregating with HMNJ in the 27 patients from 7 previously described consanguineous families and 3 newly ascertained patients. The mutant SIGMAR 1 exhibits reduced expression, altered subcellular distribution and elevates cell death when expressed. Conclusion In conclusion, the homozygous SIGMAR 1 c. $500 \mathrm{~A}>\mathrm{T}$ mutation causes dHMN of the Jerash type, possibly due to a significant drop of protein levels. This finding is in agreement with other SIGMAR1 mutations that have been associated with autosomal recessive dHMN with pyramidal signs; thus, our findings further support that SIGMAR1 be added to the dHMN genes diagnostic panel.

\section{INTRODUCTION}

Distal hereditary motor neuronopathies (dHMN) are a heterogeneous group of motor neuron disorders characterised by weakness and wasting of the distal muscles of both limbs. ${ }^{1}$ So far, 30 genes have been associated with dHMN etiopathogenesis that encode proteins involved in a variety of cellular processes, thus supporting the hypothesis that multiple pathogenetic mechanisms underlie motor neuron degeneration in dHMN. Further heterogeneity is expected in $\mathrm{dHMN}$ as mutations in the known genes only account for approximately $32.5 \%$ of patients with $\mathrm{dHMN}^{2-5}$ We previously reported a novel form of autosomal recessive dHMN; the 'Jerash type' (HMNJ) affecting seven consanguineous families in the Jerash region of Jordan. $^{67}$

SIGMAR1, encoded by the SIGMAR1 gene, is a highly conserved transmembrane endoplasmic reticulum (ER) protein, ${ }^{8}$ ubiquitously expressed in human tissues and notably enriched in motor neurons. ${ }^{9}$ SIGMAR1 mostly localises at the mitochondria-associated ER membranes (MAM) domain, where it functions as a molecular chaperone in the ER by stabilising various proteins at MAM and by participating in the degradation of misfolded proteins preventing their accumulation. ${ }^{10-12}$ Overall, SIGMAR1 is implicated in numerous cellular processes such as ion channel modulation, protein and lipid transport, ER stress response and autophagy, while agonists of SIGMAR1 have been shown to possess neuroprotective properties. ${ }^{12-16}$

Recently, homozygous or compound heterozygous SIGMAR1 mutations have been implicated in the development of $\mathrm{dHMN}$ with pyramidal signs as well as juvenile amyotrophic lateral sclerosis (jALS), two conditions sharing several phenotypical features. ${ }^{17-24}$ Here, we present functional studies in support of a novel SIGMAR1 mutation causing HMNJ, when present in homozygosity.

\section{METHODS}

\section{Patients}

In this study, 12 individuals from 3 consanguineous families with HMNJ were clinically evaluated (figure 1). Five members have progressive distal muscle weakness, while the other seven members are unaffected, some of whom having subjective complaints of pain and discomfort in the feet, on walking. Two of these families were included in our previous report. ${ }^{7}$ One patient from each previously reported family has been re-examined (B22 and C29) and a new patient (C27) has been ascertained. Two patients from a new family (A9 and A11) are also presented in this report. 


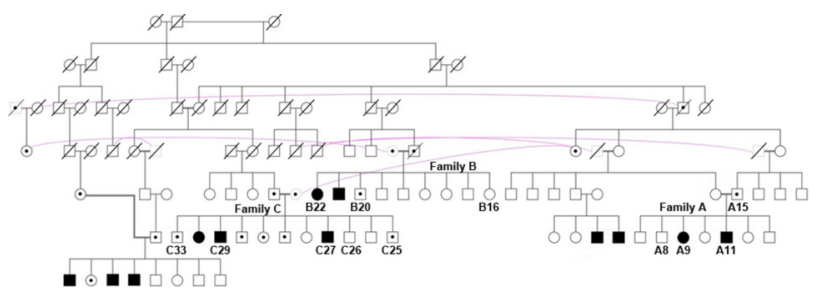

Figure 1 Pedigree structure of the three consanguineous families (A, B and C) clinically evaluated for this study. Patients with HMNJ are shown as filled symbols and are homozygous for SIGMAR $1^{\text {N1671 }}$. Heterozygous unaffected individuals are depicted with a black dot inside the symbol. Numbered white symbols represent family members that are SIGMAR $1^{\text {WT }}$ homozygous, and unnumbered white symbols show family members of unknown genotype. Purple curved lines are drawn between the same individual.

Detailed clinical history, physical and neurological examinations were performed on all 12 cases. Nerve conduction studies were performed to document the sensory and motor compound action potentials and nerve conduction velocities. Median, ulnar, common peroneal and sural nerves were examined. Electromyographic examination was performed to examine the first dorsal interosseous, vastus lateralis and tibialis anterior muscles.

\section{Subjects and samples}

The study participants described in the previous report ${ }^{7}$ were analysed at the Neurogenetics Department of the Cyprus Institute of Neurology and Genetics (CING). The new participants were analysed at the Department of Genetics of Yale University and provided written informed consent to take part in this study. The protocol was approved by the Yale Human Investigation Committee Institutional Review Board (HIC\#9512008556). The control cohort for the NGS study was comprised of 2000 previously sequenced samples of an admixture of subjects presenting with early-onset hypertension and normotensives, in an in-house database and subjects found in the NHLBI Exome Sequencing Project database and the Exome Aggregation Consortium V.0.3 database (ExAC). ${ }^{25}$

\section{Exome sequencing}

Genomic DNA from the new HMNJ family was isolated from anticoagulated whole blood using the standard SDS-Proteinase K digestion, Phenol-Chloroform extraction, Ammonium AcetateEthanol precipitation method. Genomic DNA from the other 7 HMNJ families as well as from 200 healthy individuals was available from the previous study. ${ }^{7}$

Exome sequencing was performed by the Yale Center for Genomic Analysis using the exon capture method and the Roche MedExome or Roche V2 capture reagent followed by 75 base paired-end sequencing on the Illumina HiSeq 2000 instrument. Samples were barcoded, captured and sequenced in multiplex, according to the manufacturer's protocols.

Sequence reads were aligned to the GRCh37/hg19 human reference genome using BWA-MEM local realignment. Quality score recalibration was performed using the GATK pipeline. PCR duplicates were eliminated and variants were called using the Genome Analysis Toolkit Haplotype Caller. Allele frequencies of variants were determined using the ExAC database. ${ }^{25}$ Pathogenicity of nonsynonymous rare variants was predicted using the Sift and PolyPhen tools. ${ }^{26} 27$

\section{Mutation analysis}

The Neurogenetics Department of CING performed candidate genes analysis and further targeted gene analysis on identification of the candidate mutation with Sanger sequencing. Primers were designed with Primer3 software for the analysis of genes from the candidate region and then for the candidate mutation region. Standard PCR reactions were carried out and PCR products were purified using the QIAquick PCR purification kit (Qiagen, Hilden, Germany), sequenced in both directions with the BigDye Terminator V.1.1 Cycle Sequencing Kit (ABI, California, USA) and then run on the ABI 3130xl Genetic Analyzer. The ABI SeqScape software was used to visualise, align and compare the results of the sequencing runs with the normal sequences of the genes under study. All available DNA samples of family members and control individuals were screened for the identified mutation with the appropriate pair of primers (online supplementary table S1). No other SIGMAR1 variant was detected in the patients' samples.

\section{Cell lines}

Lymphoblastoid cell lines (LCLs) were previously established from two patients with HMNJ (one male, one female) and three healthy individuals (two males, one female) following written informed consent and were cultured in Roswell Park Memorial Institute medium containing 10\% FBS (fetal bovine serum), 2 $\mathrm{mM}$ Glutamine, $50 \mathrm{U} / \mathrm{mL}$ Penicillin and $50 \mathrm{mg} / \mathrm{mL}$ Streptomycin (Biosera, Nuaille, France).

Human SH-SY5Y and HeLa as well as mouse NSC-34 cell lines were cultured in Dulbecco's Modified Eagle's medium supplemented with 10\% FBS, 2 mM Glutamine, $50 \mathrm{U} / \mathrm{mL}$ Penicillin and $50 \mathrm{mg} / \mathrm{mL}$ Streptomycin.

All cell lines were kept at $37^{\circ} \mathrm{C}$ in $5 \% \mathrm{CO}_{2}$.

\section{Expression studies in LCLs} mRNA level

Total RNA was extracted from the aforementioned LCLs of patients with HMNJ and healthy individuals, using the RNeasy Mini Kit (Qiagen). Subsequently, cDNA synthesis was performed with the Protoscript cDNA Synthesis Kit (NEB, Massachusetts, USA). Room temperature (RT)-qPCR was employed on the CFX96 system using the SsoFast EvaGreen Supermix (BioRad, California, USA). Primers specific for SIGMAR1 were used (online supplementary table S1). L19 was employed as a housekeeping gene for this analysis and three independent experiments were performed.

\section{Protein level}

Protein extracts were derived from the same LCLs, with the use of a homemade lysis buffer $(50 \mathrm{mM}$ Tris- $\mathrm{Cl} \mathrm{pH} 7.5,150 \mathrm{mM}$ $\mathrm{KCl}, 2 \mathrm{mM}$ EDTA, 0.5\% Triton $\mathrm{x}-100$, 1x Protease Inhibitor Cocktail). The samples were incubated on ice for 1 hour, sonicated three times and centrifuged at $14000 \mathrm{rpm}$ for $30 \mathrm{~min}$ at $4^{\circ} \mathrm{C}$. The supernatants were diluted in a final concentration of 1x SDS-PAGE Laemmli sample buffer, boiled for $5 \mathrm{~min}$ in $95^{\circ} \mathrm{C}$ and run in an SDS-PAGE gel. Antibodies to SIGMAR1 and GAPDH (normalisation control) were used for the analysis. Three independent experiments were carried out.

\section{Plasmid constructs and cloning}

Whole wild-type and mutant SIGMAR1-ORFs were distinctively amplified, with the use of appropriate restriction sites containing primers (online supplementary table S1), from cDNAs of a homozygous healthy individual and a patient with HMNJ, 
respectively and cloned into pEGFP-C3 (BD, California, USA) and pFLAG-CMV-2 (Sigma-Aldrich, Missouri, USA) vectors. With the employment of a Flag-tag containing forward primer and an appropriate reverse primer, Flag-tagged SIGMAR1 whole-ORFs were cloned from pFLAG-CMV-2 to the bicistronic vector pIRES2-EGFP (BD). All of the plasmid constructs were sequenced and verified to be free of any nucleotide changes in the SIGMAR1 cDNA.

\section{Expression studies in transiently transfected cell lines}

SH-SY5Y and NSC-34 cells were transfected with pIRES2EGFP-Flag-SIGMAR1 constructs so that Flag-SIGMAR1 and GFP would get cotransfected into the same cells, but expressed as two separate proteins from the same mRNA. Cells were treated with $10 \mu \mathrm{M}$ MG132 or DMSO (Sigma-Aldrich) for 6 hours. FlagSIGMAR1 protein's expression was detected using an anti-Flag antibody. RT-qPCR was also conducted to relatively quantify the mRNA levels, using primers amplifying the exogenous FlagSIGMAR1 but not the endogenous SIGMAR1. GFP protein and mRNA levels, respectively, were used for normalisation. Three independent experiments were conducted.

\section{Immunoblot analysis}

Protein electrophoresis was conducted on a Mini-PROTEAN system, and samples were transferred in a polyvinylidene difluoride membrane on a Mini Trans-blot cell (Biorad). Membranes were blocked for 1 hour in 5\% non-fat dry milk in phosphate buffered saline (PBS)/Tween, followed by incubation with the appropriate primary antibody overnight. The next day membranes were washed $3 \times 10 \mathrm{~min}$ in PBS/Tween and incubated with the appropriate secondary antibody for 1 hour. After three washes, proteins signals were visualised using the LumiSensor Chemiluminescent HRP Substrate Kit (Genscript, New Jersey, USA), in a UVP BioSpectrum Imaging System (UVP, California, USA). Data were analysed using ImageJ $1.51 \mathrm{j} 8$ software. Twotailed $t$ test was used to assess the $\mathrm{p}$ value.

\section{Immunofluorescence}

SH-SY5Y cells were grown on coverslips and 24 hours later got transiently co-transfected with the pEGFP-C3 SIGMAR1 and the ER marker mch-Sec61 beta constructs with the use of Lipofectamine 3000 (ThermoFisher, Massachusetts, USA) following the manufacturer's instructions. Plasmid mCh-Sec61 beta was a gift of Gia Voeltz. ${ }^{28}$ After 48 hours, cells were treated with $10 \mu \mathrm{M}$ MG132 or DMSO for 6 hours and then fixed for $10 \mathrm{~min}$ at RT with 4\% w/v paraformaldehyde in PBS, permeabilised with Methanol for $10 \mathrm{~min}$ at $-20^{\circ} \mathrm{C}$ and quenched for $10 \mathrm{~min}$ at RT with $50 \mathrm{mM} \mathrm{NH}_{4} \mathrm{Cl}$ in PBS. Cell nuclei were stained with Hoechst 33342 and coverslips were mounted with Dako Fluorescent Mounting Medium (Agilent, California, USA). Images were captured with a Zeiss fluorescent microscope using the Axiovision software. Colocalisation index was quantified by Manders' coefficient using Coloc2 plugin for ImageJ, and twotailed $t$ test was used to assess the p value.

\section{Antibodies}

Goat anti-SIGMAR1, mouse anti-GAPDH (Santa Cruz, Texas, USA), rabbit anti-GFP (Proteintech, Illinois, USA) and mouse anti-FLAG (Sigma-Aldrich) primary antibodies were used. Donkey anti-goat IgG HRP, donkey anti-rabbit IgG HRP (Santa Cruz) and goat anti-mouse IgG HRP (Millipore, Massachusetts, USA) were used as secondary antibodies.

\section{Terminal deoxynucleotidyl transferase dUTP Nick-End labelling (TUNEL) assay}

SH-SY5Y and HeLa cells were grown on coverslips placed in 6-well plates and 24 hours later got transiently transfected with pEGFP-C3 SIGMAR1 constructs. Forty-eight hours later cells were fixed for $10 \mathrm{~min}$ with $4 \% \mathrm{w} / \mathrm{v}$ paraformaldehyde and permeabilised for $20 \mathrm{~min}$ in $0.25 \%$ Triton-X. TUNEL assay was conducted using the Click-iT Plus TUNEL Assay for In Situ Apoptosis Detection kit (ThermoFisher). Cell nuclei were stained with Hoechst 33342; coverslips were mounted with Dako Mounting Medium and visualised on a Zeiss fluorescent microscope. The TUNEL-positive nuclei percentage of successfully transfected cells was determined through microscopic analysis of four independent experiments for SH-SY5Y and three for HeLa cells. Approximately 1000 cells were counted for each experiment. Two-tailed $t$ test was used to assess the $\mathrm{p}$ value.

\section{Data availability}

Data supporting the outcomes of this manuscript and not published within this article are available in an anonymised fashion to qualified investigators on request by directly contacting the corresponding author.

\section{RESULTS}

\section{Patient evaluation}

This study included clinical evaluation of 12 individuals from 3 consanguineous HMNJ families (figure 1): 3 females and 9 males, with ages between 10 and 58 years.

The five patients presented with progressive, symmetrical lower limb distal muscle wasting and weakness at an early age. Ankle and toe dorsiflexors were more affected than plantar flexors and evertors more than invertors. All patients had pes cavus and all walked with a high-stepping gait. Upper limb involvement were first noted in puberty with the exception of one individual who had wrist and finger extensors more affected than the flexors at a much earlier age. Two patients had mild and three had severe distal muscle weakness and wasting of the lower limbs. Proximal muscles, cranial nerves, coordination and sensory systems were intact. Knee jerks were present in all patients and brisk in all except the oldest one. All patients showed decreased or absent ankle jerks and flexor plantar response, except the youngest patient who exhibited normal ankle jerks and extensor plantar response. Pyramidal signs tend to fade away with age. Motor nerve conduction studies showed decreased compound muscle action potential amplitude with normal or slightly reduced conduction velocities in all five patients, while sensory nerve conduction studies were normal. Electromyography showed active denervation in the form of fibrillations and positive sharp waves, chronic neurogenic changes characterised by the presence of large motor units and reduced recruitment pattern on voluntary contraction of tibialis anterior and first dorsal interosseous muscles. Clinical features and neurophysiological findings were reminiscent of our previous findings. ${ }^{7}$ Furthermore, mild sensory symptoms in the form of numbness of the feet and to a lesser extent of the hands were recorded in three patients (online supplementary table S2).

Seven non-affected individuals from these three HMNJ families were also clinically evaluated. They all had normal nerve conduction studies and electromyography, no signs of muscle weakness or atrophy, normal ankle reflexes, while Babinski reflex was absent. Some of these individuals reported subjective complaints of pain and discomfort in the feet on walking, which 
A

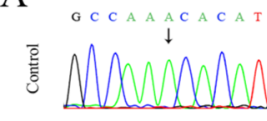

B
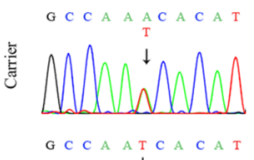

咅

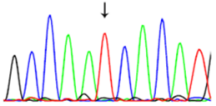
Mus muscul Bos taurus: Canis lupus: Felis catus: Equus caballus: Pelodiscus sine Gallus gallus: Xenopus tropicals
Homo sapiens:

GEATAVEWGPNTWMVEYGRGV GEATAVEWGPNTWMVEYRGV GEATAVEWGPNTWMVEYGRGV GEATAVEWGPNTWIVYGVV GEATAVEWGPNTWMEYG GEATAVEWGPNTWMVEYGRGV GEATAVQWSAGTWMVEYGRGV GEATSVWWAGTWMVYGRG GEATSVQWSAGTWMVEYGRG GEATSVQWSSGTWMVEYGRGF

C

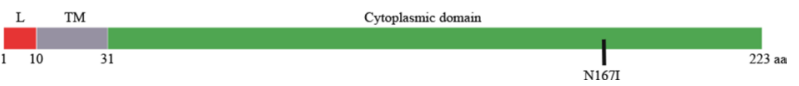

Figure 2 Identification of a homozygous missense mutation (SIGMAR $1^{\text {N1671) }}$ in patients with HMNJ. (A) Sequences demonstrating the identified mutation in genomic DNA from healthy homozygous individuals (control), their unaffected heterozygous parents (carrier) and affected individuals (patient). (B) The affected amino acid is conserved in various mammal species, but is not present in other vertebrate classes. (C) N167I is located in the cytoplasmic domain of the SIGMAR1 protein. $\mathrm{L}=$ Luminal domain. TM=Transmembrane domain. Source: UniprotKB. ${ }^{30}$

does not seem to be relevant, given the age of individuals and the normal neurophysiological findings.

\section{Identification of a novel SIGMAR1 mutation in patients with HMNJ}

HMNJ was mapped to chromosome 9p21.1-p12. ${ }^{7}$ SIGMAR1 is a gene located within this region that was previously implicated in motor neuronopathies. ${ }^{17-23}$ Exome sequencing (mean coverage depth: 159X) was performed in a patient with HMNJ and identified a homozygous missense substitution in exon 4 of the SIGMAR1 gene (rs766761162, NM 005866.4: c.500A>T, NP_005857.1: p.N167I, coverage depth: 149x, reads G.0, C.149). No variants in any other genes previously associated with dHMN or other related neuropathies were identified. Furthermore, Sanger sequencing of the 27 patients that were available in the Neurogenetics Department of the CING did not detect any other putative disease-causing variants within the coding region of SIGMAR1. In addition, no C9orf72 repeat expansions were detected in patients with HMNJ tested (data not shown), thus excluding the possibility of a cosegregating C9orf72 expansion. ${ }^{29}$

Sanger sequencing revealed the presence of the SIGMAR1 variant in a homozygous state, in all 30 affected individuals of the $8 \mathrm{HMNJ}$ consanguineous families. All unaffected parents were identified to be heterozygous while the remaining healthy individuals of the HMNJ families tested, had a single or no copy of the variant (figure $2 \mathrm{~A}$ ). The variant was absent in 100 unrelated healthy control individuals tested. According to ExAC, ${ }^{25}$ this is an extremely rare variant that has been identified before in a heterozygous state in only one person out of 60638 worldwide. This SIGMAR1 gene missense mutation causes a single aminoacid substitution (p.Asn167lle), in which a polar amino acid (Asparagine) is replaced by a hydrophobic amino acid (Isoleucine) within the cytoplasmic domain of the protein (figure 2C), according to UniProtKB. ${ }^{30}$ The substituted amino acid is well conserved among mammals, but it is not found in other vertebrate classes (figure $2 \mathrm{~B}$ ). Moreover, the identified mutation is predicted to be deleterious by several in silico analysis algorithms,
A

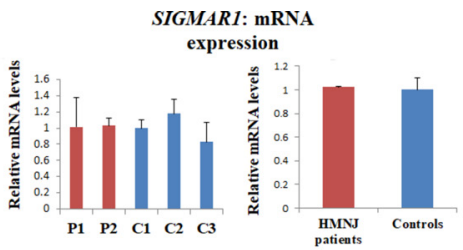

B

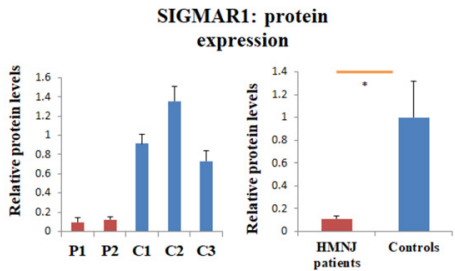

C

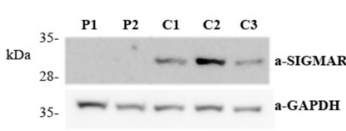

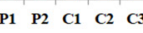

patients
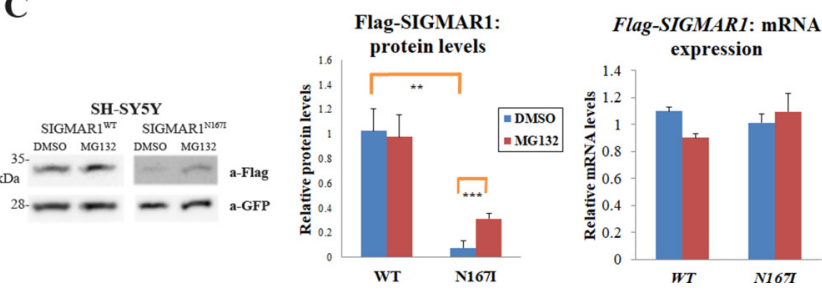

Figure 3 N167l mutation causes reduction in SIGMAR1's expression levels. (A) qPCR revealed that SIGMAR1 mRNA expression in LCLs is similar in patients and healthy individuals. The graphs show the relative SIGMAR1 mRNA levels of patients with HMNJ and controls (individually and grouped), after normalisation with the ribosomal protein L19 gene. Error bars depict the SE of the mean (SEM) of three independent triplicate experiments. (B) WB showing that the endogenous protein levels of the SIGMAR1 mutated form from lymphoblastoid cells of patients with HMNJ are reduced in comparison to the control lymphoblastoid samples from healthy individuals, expressing the wild-type SIGMAR1. The graphs show the relative SIGMAR1 protein levels of patients with HMNJ and controls (individually and grouped), after normalisation with the GAPDH protein levels, derived from densitometric quantification of the SIGMAR1 and the GAPDH proteins expression. Error bars depict the SD of three independent experiments. (C) The employment of a GFP-bicistronic vector system reveals a significant drop in protein levels in the case of the heterologous Flag-SIGMAR1 ${ }^{\mathrm{N} 1671}$ in comparison to Flag-SIGMAR1 ${ }^{\mathrm{WT}}$, in SH-SY5Y $(p=0.001890994)$ cells. In the presence of MG132, Flag-SIGMAR $1^{\text {N1671 }}$ protein levels were elevated $(p=0.000750874)$, demonstrating that the mutant SIGMAR1 undergoes ubiquitin-mediated degradation. $\mathrm{GPCR}$ showed no significant differences between the wild-type and the mutant heterologous mRNAs, in basal conditions or after MG132 treatment. Error bars depict the SD in the proteins' expression graph, and the SE of the mean (SEM) in the mRNA expression graph, of three independent experiments. GFP protein and mRNA levels were used for normalisation.

such as SIFT (score 0.02: damaging) and PolyPhen (score 0.984: probably damaging). ${ }^{2627}$

\section{HMNJ SIGMAR1 ${ }^{\text {N1671 }}$ aberrant expression and localisation}

To compare the endogenous expression between SIGMAR $1^{\text {WT }}$ and SIGMAR1 ${ }^{\mathrm{N} 167 \mathrm{I}}$, we used mRNA and protein extracts from LCLs derived from blood of healthy individuals and patients with HMNJ. SDS-PAGE and Western-blot (WB) analysis revealed that SIGMAR1 ${ }^{\mathrm{N} 167 \mathrm{I}}$ protein levels are reduced to $11.17 \% \pm 2.1 \%$ (SD) in comparison to SIGMAR1 ${ }^{\mathrm{WT}}(\mathrm{p}=0.03)$ (figure $\left.3 \mathrm{~B}\right)$. Interestingly, RT-qPCR showed no significant differences between the mRNA expression of SIGMAR1 $1^{\text {WT }}$ and SIGMAR1 $1^{\text {N167I }}$ (figure $3 \mathrm{~A}$ ), indicating that the reduction in the expression levels is occurring at the protein level. 
To verify this finding, we transiently transfected pIRES2EGFP constructs expressing (1) Flag-SIGMAR1 ${ }^{\text {WT }}$ and GFP and (2) Flag-SIGMAR1 $1^{\text {N167I }}$ and GFP and measured the protein levels of the exogenous Flag-SIGMAR1s. GFP levels were used for normalisation. The expression of Flag-SIGMAR1 ${ }^{\text {N167I }}$ was almost diminished in comparison to Flag-SIGMAR $1^{\text {WT }}$ expression in the human SH-SY5Y cell line (13,41-fold reduction, $\mathrm{p}=0.0019)$. Less but still significant reduction was observed in mouse NSC-34 cells (2.2-fold reduction, $p=0.0004)$. Given that the endogenous reduction in expression is occurring at the protein level, we compared the protein expression of the two forms in relation to treatment with the proteasome inhibitor MG132. In the presence of MG132, the exogenous levels of Flag-SIGMAR1 ${ }^{\text {N67I }}$ were elevated compared with basal conditions, demonstrating that SIGMAR1 ${ }^{\mathrm{N} 167 \mathrm{I}}$ is degraded through the ubiquitin-proteasome pathway (figure 3C). In SH-SY5Y cells, the expression of Flag-SIGMAR1 ${ }^{\text {N167I }}$ showed a 4.06fold increase $(p=0.00075)$ after MG132 treatment, while in NSC-34 cells the expression of Flag-SIGMAR1 ${ }^{\text {N167I }}$ displayed a 1.99-fold increase after MG132 treatment. RT-qPCR showed no significant differences between the mRNA expression of the two isoforms, under basal or proteasome inhibition conditions. SH-SY5Y data are presented in figure 3C, while NSC-34 data can be found in online supplementary figure $\mathrm{S} 1$.

Further evidence of the reduction in the expression of SIGMAR1 ${ }^{\text {N167I }}$ is given through immunofluorescence experiments. GFP-SIGMAR1 ${ }^{\text {N167I }}$ fluorescence levels were lower in comparison to GFP-SIGMAR1 in SH-SY5Y cells. As in the case of Flag-SIGMAR1 ${ }^{\text {N167I }}$, when the cells expressing GFPSIGMAR1 $1^{\text {N167I }}$ were treated with MG132, SIGMAR1 levels were raised (figure 4).

Immunofluorescence also showed that even though GFPSIGMAR $1^{\text {N167I }}$ retains its localisation to the ER, it exhibits a more diffused distribution in comparison to the granular allocation of GFP-SIGMAR $1^{\text {WT }}$ in SH-SY5Y cells. Manders' overlap coefficient analysis showed that SIGMAR1 ${ }^{\text {N167I }}$ colocalises with Sec61b at a higher degree than SIGMAR ${ }^{\text {WT }}(\mathrm{p}<0001)$ (figures 4 and $5 \mathrm{~A})$.

\section{SH-SY5Y cells expressing GFP-SIGMAR $1^{\mathrm{N} 1671}$ show induced apoptosis}

Following our observation that GFP-SIGMAR1 ${ }^{\text {N167I }}$ is degraded through the ubiquitin-proteasome pathway, we proceeded to assess whether its overexpression would cause apoptosis. We employed the TUNEL assay to count the percentage of apoptotic nuclei in transiently transfected SH-SY5Y cells with (1) GFP-SIGMAR1 $1^{\text {WT }}$, (2) GFP-SIGMAR1 ${ }^{\text {N167I }}$ and (3) mock cells. The measurements unravelled a statistically significant increase of apoptosis in the GFP-SIGMAR $1^{\text {N167I }}$ transfected cells in comparison to the GFP-SIGMAR $1^{W T}$ expressing cells under physiological conditions (with $19.65 \pm 2.93$ vs $6.70 \pm 1.58 \%$ SD, $\mathrm{p}=0.006233$ ) and also in comparison to mock (with $19.65 \pm 2.93$ vs $6.13 \% \pm 0.78 \%, \mathrm{p}=0.005123)$. For validation purposes the experiment was repeated in HeLa cells with similar results (with $14.13 \pm 0.81$ in GFP-SIGMAR1 ${ }^{\text {N167I }}, 5.33 \% \pm 1.55 \%$ in GFPSIGMAR $1^{W T}$ and $4.04 \% \pm 0.28 \%$ in mock cells, $\mathrm{p}=0.022825$ for N167I vs WT, $\mathrm{p}=0.001634$ for N167I vs mock). SIGMAR1 $1^{\text {WT }}$ overexpression did not have any effect on apoptosis in basal conditions (figure 5B).

\section{DISCUSSION}

We have identified a homozygous SIGMAR1 c.500A > T (N167I) missense mutation cosegregating with $\mathrm{HMNJ}$; an extremely rare
A

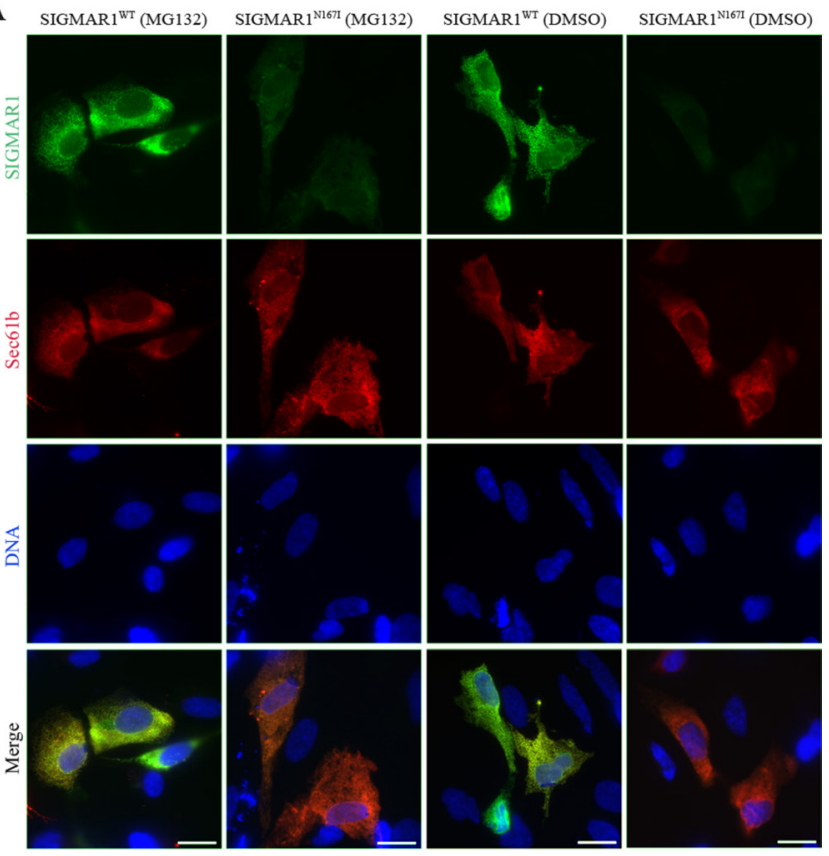

B

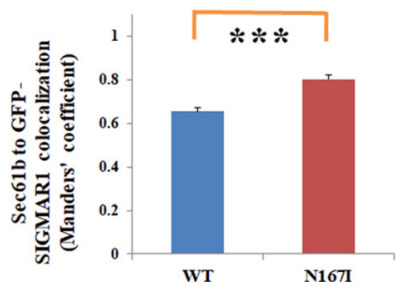

Figure 4 Intracellular localisation of GFP-SIGMAR $1^{\text {WT }}$ and GFPSIGMAR1 ${ }^{\text {N1671 }}$. (A) SIGMAR1 ${ }^{\text {WT }}$ and SIGMAR $1^{\text {N1671 }}$ (green) retain colocalisation with endoplasmic reticulum marker Sec61b (red), in the presence or absence of proteasomal inhibitor MG132. Blue colour represents the nuclei. SIGMAR ${ }^{\mathrm{N} 1671}$ is showing a lower expression level that is raised in the presence of MG132, consistent with the WB findings of endogenous and exogenous SIGMAR1s in figure 2. Green colour's exposure is identical in every condition to depict the SIGMAR1 expression differences between them. Scale bars $20 \mu \mathrm{m}$. (B) Graph displaying Manders' coefficient quantification (fraction of Sec61b colocalising with GFP-SIGMAR1 wildtype or mutant) calculated from at least 40 fluorescence microscopy images for each isoform in basal conditions. Error bars depict the SEM of three independent experiments.

variant, based on data from several online browsers and tools. Our findings suggest a loss-of-function effect. The aminoacid change affects SIGMAR1 isoform mSIG-1A, which is the sole brain-specific isoform out of seven in mice. ${ }^{31}$

Our study included individuals of one newly diagnosed HMNJ pedigree, in addition to individuals from two previously described HMNJ families. The main clinical features such as distal weakness, wasting and the pyramidal signs fading with age were similar to that of our previous report as well as to the other SIGMAR1-associated dHMNs. ${ }^{78}{ }^{20-24}$ Furthermore, nerve conduction studies and electromyography findings were also comparable to those observed in other SIGMAR1-associated dHMNs and in our previous HMNJ report. ${ }^{78} 202123$ Spasticity in the lower limbs, present in the Omani and the British kindred, ${ }^{22} 23$ was also present in the patients with HMNJ, unlike the other SIGMAR1-associated dHMN cases.

In recent years, various SIGMAR1 mutations were found to be associated with the development of dHMN with or without 


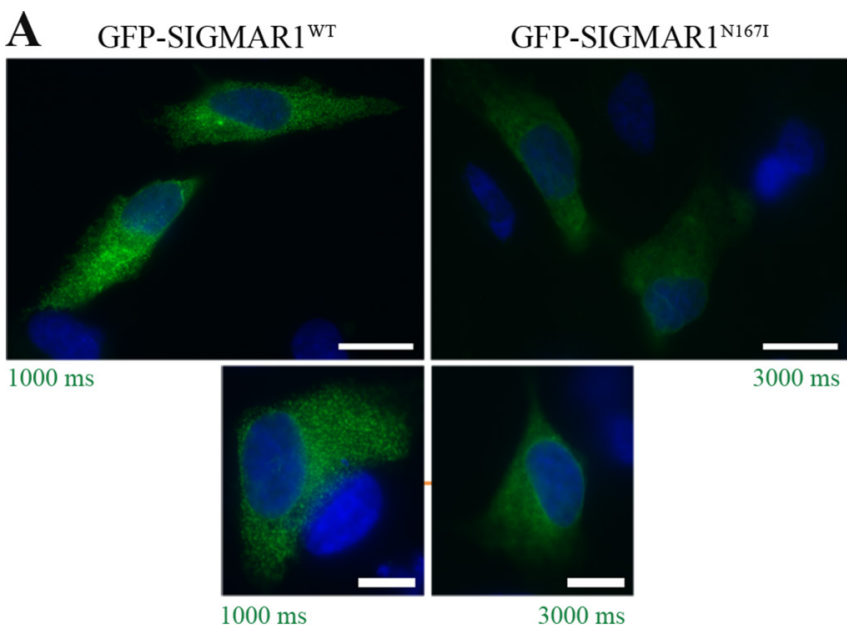

B

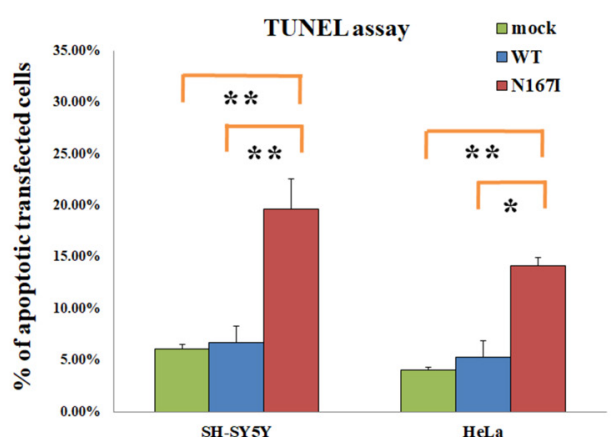

Figure 5 Exogenous GFP-SIGMAR $1^{\mathrm{HMNJ}}$ expression consequences in the protein's localisation and cell viability: (A) SIGMAR $1^{\mathrm{N} 1671}$ is distributed in a more diffused fashion in comparison to the granular localisation of SIGMAR $1^{\text {WT }}$. Green colour's exposure is three times higher in the case of SIGMAR ${ }^{\mathrm{N} 1671}$. Scale bars $10 \mu \mathrm{m}$ in the upper and $5 \mu \mathrm{m}$ in the lower images. (B) GFP-SIGMAR1 ${ }^{\text {N167l's }}$ s expression induces apoptosis in SH-SY5Y $(p=0.006)$ and HeLa cells $(p=0.023)$, in comparison to GFP-SIGMAR $1^{\text {WT }}$ expression. Additionally, GFP-SIGMAR $1^{\mathrm{N} 1671}$ s expression induces apoptosis in SH-SY5Y ( $p=0.005)$ and HeLa cells $(p=0.002)$, in comparison to mocktransfected cells as well. No significant differences were found between the mock-transfected and the cells expressing GFP-SIGMAR $1^{\text {WT }}$. Error bars depict the SD of four independent experiments for SH-SY5Y and three for HeLa cells.

spasticity and jALS; however the number of identified patients was low in every SIGMAR1 neuropathogenic mutation with maximum 4 patients with $\mathrm{dHMN}$ associated to c. $151+1 \mathrm{G}>\mathrm{T}$ and 6 patients with jALS to c.304G $>$ C. ${ }^{17-24}$ We report for the first time a SIGMAR1 mutation associated with a neurodegenerative disease in a large number of patients. The SIGMAR1induced neuronopathies display autosomal-recessive inheritance and exhibit common symptoms like onset in the first or second decade of the patients' life, progressive weakness and wasting initially of the lower and then of the upper limbs and absence of any sensory abnormalities. The phenotypic spectrum of verified SIGMAR1-induced neuronopathies is presented in table $1 .^{717-24}$ Also recently, compound heterozygous SIGMAR1 mutations were reported in a patient with oldest-old onset ALS. ${ }^{32}$ However, confirmation of pathogenicity of these mutations with functional studies has not been reported.

The finding of a plethora of SIGMAR1 mutations in disease nosology is not unusual; indeed, several mutations reported in other molecular chaperones such as HSPB1 and HSPB 8 cause a variety of neuropathies like Charcot-Marie-Tooth Disease,
dHMN and ALS. ${ }^{3} 43-37$ Nevertheless, dHMNs with prominent pyramidal signs are considered as forms of jALS, because of the phenotypic similarities they share with these conditions, especially with the autosomal dominant form known as ALS4. ${ }^{38-40}$ The cellular phenotypes that SIGMAR1 $1^{\text {N167I }}$ is causing, such as reduction of SIGMAR1 protein expression, abnormal localisation and elevated apoptosis, have been observed before in studies of other SIGMAR1 mutations associated with dHMN and jALS. ${ }^{17-19} 2141$

Based on our findings of mRNA levels not significantly reduced and mutant protein levels increased in the presence of a proteasomal inhibitor, we propose that the drop in SIGMAR1 ${ }^{\text {N167I }}$ expression levels is probably due to misfolding, which leads to the proteasomal degradation of the protein. This trimming in SIGMAR1 protein levels was also observed in other possibly misfolded pathogenic SIGMAR1 mutants like the E102Q, L95fs, ${ }^{19}$ and 31_50del ${ }^{18}$ causing jALS and dHMN, respectively. It is thus critical for the endogenous SIGMAR1 protein levels to be maintained above an appropriate threshold.

The observed diffused subcellular localisation of SIGMAR1 ${ }^{\text {N167I }}$ has also been reported for the SIGMAR1 31_50del, ${ }^{41}$ E138Q and E150K ${ }^{21}$ mutants causing dHMN, while the jALS-causing E102Q mutant localisation is also aberrant since it forms large puncta. ${ }^{1741}$ All these mutations likely disrupt the physiological localisation of SIGMAR1 at the MAM. It is likely that due to SIGMAR $1^{\mathrm{N} 167 \mathrm{I}}$ misfolding, the tertiary structure is affected and the mutant has reduced capability of attaching to the MAM, thus remaining cytoplasmically diffused. On the other hand, a possibility could be that the trimeric form of SIGMAR $1^{42}$ is disrupted because of the aminoacid replacement, resulting in the dispersed localisation state that SIGMAR1 $1^{\text {N167I }}$ is found, rather than the granular and compact pattern of the SIGMAR $1^{\text {WT }}$.

Furthermore, SIGMAR1 pathogenic mutants have in common the increase in apoptosis levels. Besides the HMNJ causing N167I mutant that we showed to elevate cell death, the same has been reported for other dHMN-causing mutants such as $3150 \mathrm{del},{ }^{18} \mathrm{E} 138 \mathrm{Q}$ and $\mathrm{E} 150 \mathrm{~K},{ }^{21}$ as well as for the jALScausing E102Q mutant. ${ }^{17} 43$ Therefore, SIGMAR1 is important for cell survival. In addition, even though these mutations are pathogenic only in homozygosity, in the cell lines tested they increased apoptosis in the presence of the endogenous wild-type SIGMAR1. Therefore, when these mutants are overexpressed, they may antagonise with the WT in terms of binding and/or protein-protein interactions.

Reports from in vitro experiments indicate that SIGMAR1 knockdown causes calcium homeostasis defects, ER stress activation and thus apoptosis enhancement. ${ }^{10} 1444$ Knockout mice exhibit motor neuron axonal degeneration and death and muscle weakness leading to locomotor deficiency. This is due to MAM disruption, impaired $\mathrm{Ca}^{2+}$ signalling and ER stress activation. Despite the motor defects, the SIGMAR1 knockout mice remain viable, fertile and ambulant. No abnormalities were detected in the sensory neurons, highlighting the specificity and necessity for SIGMAR1's function in motor neurons. ${ }^{45} 46$ The benign course of SIGMAR1 knockout mice and the presence of motor but not sensory features resemble HMNJ.

Moreover, the c.238C $>\mathrm{T}$ SIGMAR1 truncating mutation (p.Gln80*), which totally diminishes SIGMAR1 protein expression, was identified as the causative factor for dHMN with pyramidal signs in an Omani consanguineous family that is very similar phenotypically with the HMNJ. ${ }^{23}$ This constitutes a strong indication that SIGMAR1 reduction may be the underlying reason for $\mathrm{dHMN}$ development. 


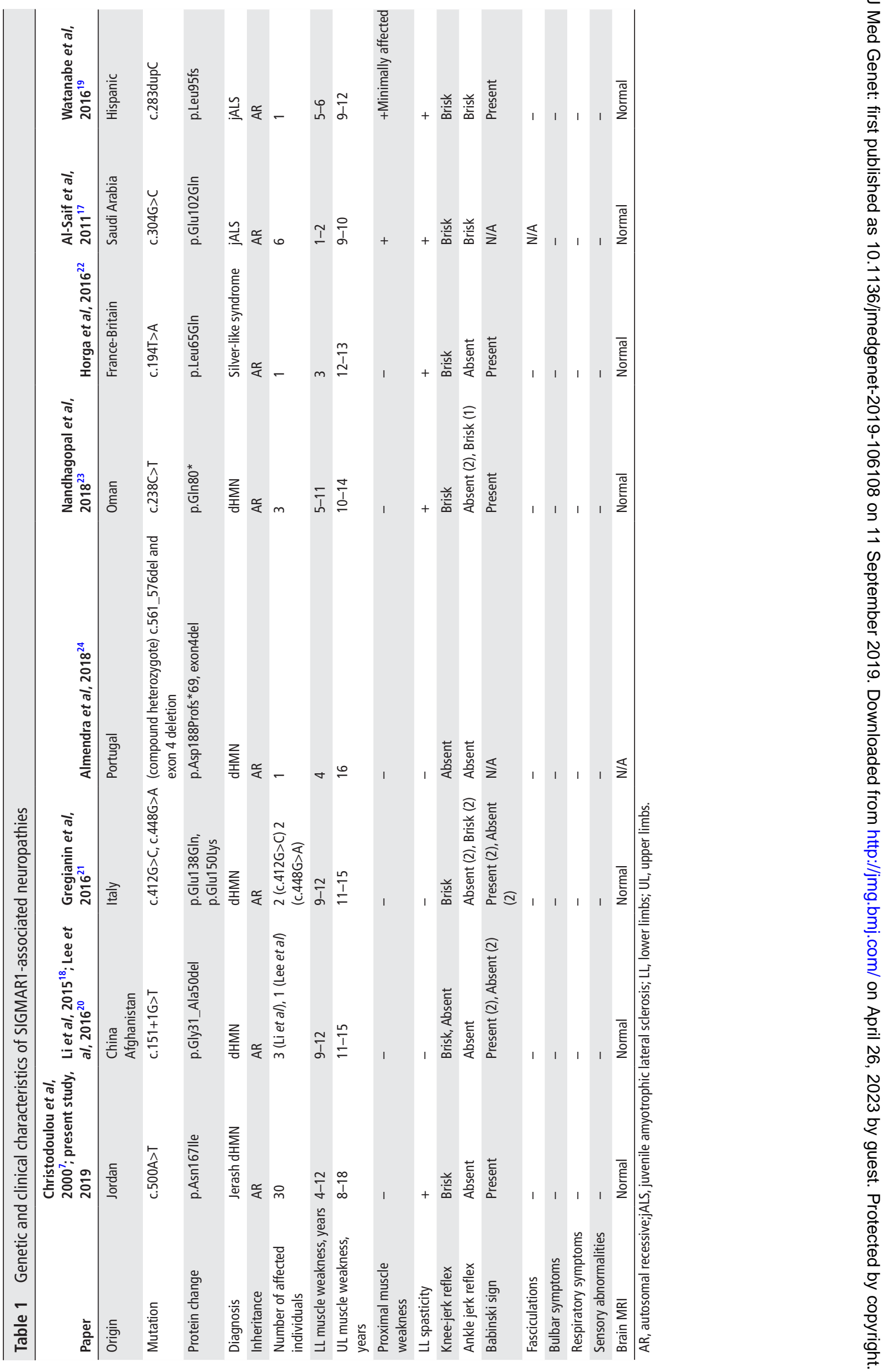


We consider the HMNJ phenotype to develop due to a SIGMAR1 loss of function, since endogenous and exogenous SIGMAR $1^{\text {N167I }}$ expression is diminished. SIGMAR $1^{\text {N167I }}$ homozygosity may leave cells without an efficient SIGMAR1 concentration to carry its subcellular tasks, thus leading to HMNJ.

In conclusion, our findings add further evidence to suggest that SIGMAR1 mutations are implicated in the aetiology of dHMN with mild pyramidal signs and jALS, as also supported by others. ${ }^{17-24}$ In the light of such compelling evidence, as previously proposed, ${ }^{20}{ }^{23}$ it would be advisable that SIGMAR1 mutations are included in diagnostic panels for dHMNs, in the interest of patients with these conditions, as well as for the design of prevention strategies, in the context of public health.

\section{Author affiliations}

${ }^{1}$ Neurogenetics Department, The Cyprus Institute of Neurology and Genetics, Nicosia, Cyprus

${ }^{2}$ Cyprus School of Molecular Medicine, The Cyprus Institute of Neurology and Genetics, Nicosia, Cyprus

${ }^{3}$ Department of Biology and Biotechnology, Hashemite University, Zarqa, Jordan

${ }^{4}$ Department of Computer Science, Hashemite University, Zarqa, Jordan

${ }^{5}$ Department of Genetics, Yale University, New Haven, Connecticut, USA

${ }^{6}$ Neurology Department, King Hussein Medical Centre, Amman, Jordan

${ }^{7}$ College of Medicine, University of Jordan, Amman, Jordan

${ }^{8}$ Keck School of Medicine, University of Southern California, Los Angeles,

Connecticut, USA

${ }^{9}$ Ageing Epidemiology (AGE) Research Unit, School of Public Health, Imperial College London, London, UK

${ }^{10}$ Neurology Clinic D, The Cyprus Institute of Neurology and Genetics, Nicosia, Cyprus

Acknowledgements The authors thank the patients and their family members for participating in this study.

Contributors All authors contributed to the accrual of subjects and/or data. AV, $\mathrm{RD}, \mathrm{AAAQ}$ and $K C$ contributed to the conception and design of the study and drafted the manuscript. All authors have revised the manuscript for important intellectual content and approved the final version.

Funding This study was supported by the Muscular Dystrophy Association of the United States (Christodoulou K), the Cyprus Telethon (Christodoulou K) and Howard Hughes Medical Investigator (HHMI) funding (Lifton R).

Competing interests None declared.

Patient consent for publication Not required.

Ethics approval Yale Human Investigation Committee Institutional Review Board (HIC\#9512008556).

Provenance and peer review Not commissioned; externally peer reviewed.

Data availability statement Data are available on reasonable request.

Open access This is an open access article distributed in accordance with the Creative Commons Attribution Non Commercial (CC BY-NC 4.0) license, which permits others to distribute, remix, adapt, build upon this work non-commercially, and license their derivative works on different terms, provided the original work is properly cited, appropriate credit is given, any changes made indicated, and the use is non-commercial. See: http://creativecommons.org/licenses/by-nc/4.0/.

\section{ORCID iD}

Kyproula Christodoulou http://orcid.org/0000-0002-0622-7594

\section{REFERENCES}

1 Irobi J, Dierick I, Jordanova A, Claeys KG, De Jonghe P, Timmerman V. Unraveling the genetics of distal hereditary motor neuronopathies. Neuromolecular Med 2006:8:131-46.

2 P. Drew A, P. Blair I, A. Nicholson G. Molecular genetics and mechanisms of disease in distal hereditary motor neuropathies: insights directing future genetic studies. Curr Mol Med 2011;11:650-65

3 Stojkovic T. Hereditary neuropathies: an update. Rev Neurol 2016;172:775-8.

4 Lupo V, Aguado C, Knecht E, Espinós C. Chaperonopathies: spotlight on hereditary motor neuropathies. Front. Mol. Biosci. 2016;3.

5 Bansagi B, Griffin H, Whittaker RG, Antoniadi T, Evangelista T, Miller J, Greenslade M, Forester N, Duff J, Bradshaw A, Kleinle S, Boczonadi V, Steele H, Ramesh V, Franko E, Pyle A, Lochmüller H, Chinnery PF, Horvath R. Genetic heterogeneity of motor neuropathies. Neurology 2017;88:1226-34.
6 Middleton LT, Christodoulou K, Mubaidin A, Zamba E, Tsingis M, Kyriacou K, Abu-Sheikh S, Kyriakides T, Neocleous V, Georgiou DM, el-Khateeb M, al-Qudah A Horany K. Distal hereditary motor neuronopathy of the Jerash type. Ann NY Acad Sci 1999:883:439-42.

7 Christodoulou K, Zamba E, Tsingis M, Mubaidin A, Horani K, Abu-Sheik S, El-Khateeb M, Kyriacou K, Kyriakides T, Al-Qudah A-K, Middleton L. A novel form of distal hereditary motor neuronopathy maps to chromosome 9p21.1-p12. Ann Neurol 2000:48:877-84.

8 Kekuda R, Prasad PD, Fei Y-J, Leibach FH, Ganapathy V. Cloning and functional expression of the human type 1 sigma receptor (hSigmaR1). Biochem Biophys Res Commun 1996;229:553-8.

9 Mavlyutov TA, Epstein ML, Andersen KA, Ziskind-Conhaim L, Ruoho AE. The sigma-1 receptor is enriched in postsynaptic sites of C-terminals in mouse motoneurons. An anatomical and behavioral study. Neuroscience 2010;167:247-55.

10 Hayashi T, Su T-P. Sigma-1 receptor chaperones at the ER- mitochondrion interface regulate Ca2+ signaling and cell survival. Cell 2007;131:596-610.

11 Hayashi T, Tsai S-Y, Mori T, Fujimoto M, Su T-P. Targeting ligand-operated chaperone sigma-1 receptors in the treatment of neuropsychiatric disorders. Expert Opin Ther Targets 2011;15:557-77.

12 Mori T, Hayashi T, Hayashi E, Su T-P. Sigma-1 receptor chaperone at the ERmitochondrion interface mediates the mitochondrion-ER-nucleus signaling for cellular survival. PLoS One 2013;8:e76941.

13 Maurice T, Su T-P. The pharmacology of sigma-1 receptors. Pharmacol Ther 2009;124:195-206.

14 Prause J, Goswami A, Katona I, Roos A, Schnizler M, Bushuven E, Dreier A Buchkremer S, Johann S, Beyer C, Deschauer M, Troost D, Weis J, localization A. Altered localization, abnormal modification and loss of function of sigma receptor-1 in amyotrophic lateral sclerosis. Hum Mol Genet 2013;22:1581-600.

15 MacVicar T, Mannack L, Lees R, Lane J. Targeted siRNA screens identify ER-toMitochondrial calcium exchange in autophagy and mitophagy responses in RPE1 cells. Int J Mol Sci 2015;16:13356-80.

16 Nguyen L, Lucke-Wold BP, Mookerjee SA, Cavendish JZ, Robson MJ, Scandinaro AL, Matsumoto RR. Role of sigma-1 receptors in neurodegenerative diseases. J Pharmacol Sci 2015;127:17-29.

17 Al-Saif A, Al-Mohanna F, Bohlega S. A mutation in sigma-1 receptor causes juvenile amyotrophic lateral sclerosis. Ann Neurol 2011;70:913-9.

18 Li X, Hu Z, Liu L, Xie Y, Zhan Y, Zi X, Wang J, Wu L, Xia K, Tang B, Zhang R. A SIGMAR1 splice-site mutation causes distal hereditary motor neuropathy. Neurology 2015;84:2430-7.

19 Watanabe S, llieva H, Tamada H, Nomura H, Komine O, Endo F, Jin S, Mancias P, Kiyama H, Yamanaka K. Mitochondria-Associated membrane collapse is a common pathomechanism in SIGMAR1- and SOD1-linked ALS. EMBO Mol Med 2016;8:1421-37

20 Lee JJY, van Karnebeek CDM, Drögemoller B, Shyr C, Tarailo-Graovac M, Eydoux P Ross CJ, Wasserman WW, Björnson B, WU JK. Further validation of the SIGMAR 1 c. 151+1G $>$ T mutation as cause of distal hereditary motor neuropathy. Child Neurol Open 2016;3:2329048X16669912.

21 Gregianin E, Pallafacchina G, Zanin S, Crippa V, Rusmini P, Poletti A, Fang M, Li Z, Diano L, Petrucci A, Lispi L, Cavallaro T, Fabrizi GM, Muglia M, Boaretto F, Vettori A, Rizzuto R, Mostacciuolo ML, Vazza G. Loss-of-function mutations in the SIGMAR1 gene cause distal hereditary motor neuropathy by impairing ER-mitochondria tethering and $\mathrm{Ca}^{2+}$ signalling. Hum Mol Genet 2016;25:3741-53.

22 Horga A, Tomaselli PJ, Gonzalez MA, Laurà M, Muntoni F, Manzur AY, Hanna MG, Blake JC, Houlden H, Züchner S, Reilly MM. SIGMAR1 mutation associated with autosomal recessive Silver-like syndrome. Neurology 2016;87:1607-12.

23 Nandhagopal R, Meftah D, Al-Kalbani S, Scott P. Recessive distal motor neuropathy with pyramidal signs in an Omani kindred: underlying novel mutation in the SIGMAR 1 gene. Eur J Neurol 2018;25:395-403.

24 Almendra L, Laranjeira F, Fernández-Marmiesse A, Negrão L. SIGMAR1 gene mutation causing Distal Hereditary Motor Neuropathy in a Portuguese family. Acta Myol 2018;37:2-4.

25 Lek M, Karczewski KJ, Minikel EV, Samocha KE, Banks E, Fennell T, O'Donnell-Luria AH, Ware JS, Hill AJ, Cummings BB, Tukiainen T, Birnbaum DP, Kosmicki JA, Duncan LE, Estrada K, Zhao F, Zou J, Pierce-Hoffman E, Berghout J, Cooper DN, Deflaux N, DePristo M, Do R, Flannick J, Fromer M, Gauthier L, Goldstein J, Gupta N, Howrigan D, Kiezun A, Kurki MI, Moonshine AL, Natarajan P, Orozco L, Peloso GM, Poplin R, Rivas MA, Ruano-Rubio V, Rose SA, Ruderfer DM, Shakir K, Stenson PD, Stevens C, Thomas BP, Tiao G, Tusie-Luna MT, Weisburd B, Won H-H, Yu D, Altshuler DM, Ardissino D, Boehnke M, Danesh J, Donnelly S, Elosua R, Florez JC, Gabriel SB, Getz G, Glatt SJ, Hultman CM, Kathiresan S, Laakso M, McCarroll S, McCarthy MI, McGovern D, McPherson R, Neale BM, Palotie A, Purcell SM, Saleheen D, Scharf JM, Sklar P, Sullivan PF, Tuomilehto J, Tsuang MT, Watkins HC, Wilson JG, Daly MJ, MacArthur DG, Exome Aggregation C. Analysis of protein-coding genetic variation in 60,706 humans. Nature 2016:536:285-91.

26 Adzhubei IA, Schmidt S, Peshkin L, Ramensky VE, Gerasimova A, Bork P, Kondrashov AS, Sunyaev SR. A method and server for predicting damaging missense mutations. Nat Methods 2010;7:248-9. 
27 Sim N-L, Kumar P, Hu J, Henikoff S, Schneider G, Ng PC. SIFT web server: predicting effects of amino acid substitutions on proteins. Nucleic Acids Res 2012;40:W452-7.

28 Zurek N, Sparks L, Voeltz G. Reticulon short hairpin transmembrane domains are used to shape ER tubules. Traffic 2011;12:28-41.

29 Dobson-Stone C, Hallupp M, Loy CT, Thompson EM, Haan E, Sue CM, Panegyres PK, Razquin C, Seijo-Martínez M, Rene R, Gascon J, Campdelacreu J, Schmoll B, Volk AE, Brooks WS, Schofield PR, Pastor P, Kwok JBJ. C90rf72 repeat expansion in Australian and Spanish frontotemporal dementia patients. PLoS One 2013;8:e56899.

30 UniProt Consortium T. UniProt: the universal protein knowledgebase. Nucleic Acids Res 2018;46:2699.

31 Pan L, Pasternak DA, Xu J, Xu M, Lu Z, Pasternak GW, Pan Y-X. Isolation and characterization of alternatively spliced variants of the mouse sigma1 receptor gene, SIGMAR1. PLoS One 2017;12:e0174694.

32 Izumi Y, Morino H, Miyamoto R, Matsuda Y, Ohsawa R, Kurashige T, Shimatani Y, Kaji R, Kawakami H. Compound heterozygote mutations in the SIGMAR1 gene in an oldest-old patient with amyotrophic lateral sclerosis. Geriatr Gerontol Int 2018;18:1519-20.

33 Evgrafov OV, Mersiyanova I, Irobi J, Van Den Bosch L, Dierick I, Leung CL, Schagina O, Verpoorten N, Van Impe K, Fedotov V, Dadali E, Auer-Grumbach M, Windpassinger C, Wagner K, Mitrovic Z, Hilton-Jones D, Talbot K, Martin J-J, Vasserman N, Tverskaya S, Polyakov A, Liem RKH, Gettemans J, Robberecht W, De Jonghe P, Timmerman V. Mutant small heat-shock protein 27 causes axonal Charcot-Marie-Tooth disease and distal hereditary motor neuropathy. Nat Genet 2004;36:602-6.

34 Irobi J, Impe KV, Seeman P, Jordanova A, Dierick I, Verpoorten N, Michalik A, Vriendt ED, Jacobs A, Gerwen VV, Vennekens Krist'I, Mazanec R, Tournev I, Hilton-Jones D, Talbot K, Kremensky I, Bosch LVD, Robberecht W, Vandekerckhove J, Broeckhoven CV Gettemans J, Jonghe PD, Timmerman V. Hot-Spot residue in small heat-shock protein 22 causes distal motor neuropathy. Nat Genet 2004;36:597-601.

35 Dierick I, Irobi J, Janssens S, Theuns J, Lemmens R, Jacobs A, Corsmit E, Hersmus N, Van Den Bosch L, Robberecht W, De Jonghe P, Van Broeckhoven C, Timmerman V. Genetic variant in theHSPB1 promoter region impairs the HSP27 stress response. Hum Mutat 2007;28:830
36 DiVincenzo C, Elzinga CD, Medeiros AC, Karbassi I, Jones JR, Evans MC, Braastad CD, Bishop CM, Jaremko M, Wang Z, Liaquat K, Hoffman CA, York MD, Batish SD, Lupski $J R$, Higgins JJ. The allelic spectrum of Charcot-Marie-Tooth disease in over 17,000 individuals with neuropathy. Mol Genet Genomic Med 2014;2:522-9.

37 Nakhro K, Park J-M, Kim YJ, Yoon BR, Yoo JH, Koo H, Choi B-O, Chung KW. A novel Lys 141Thr mutation in small heat shock protein 22 (HSPB8) gene in Charcot-MarieTooth disease type 2L. Neuromuscul Disord 2013;23:656-63.

38 Orban P, Devon RS, Hayden MR, Leavitt BR. Chapter 15 juvenile amyotrophic latera sclerosis. Handb Clin Neurol 2007;82:301-12.

39 Darras BT. Neuromuscular disorders of infancy, childhood, and adolescence : a clinician's approach. London: Academic Press, 2015.

40 Rabin BA, Griffin JW, Crain BJ, Scavina M, Chance PF, Cornblath DR. Autosomal dominant juvenile amyotrophic lateral sclerosis. Brain 1999;122:1539-50.

41 Wong AYC, Hristova E, Ahlskog N, Tasse L-A, Ngsee JK, Chudalayandi P, Bergeron R. Aberrant subcellular dynamics of sigma-1 receptor mutants underlying neuromuscular diseases. Mol Pharmacol 2016;90:238-53.

42 Schmidt HR, Zheng S, Gurpinar E, Koehl A, Manglik A, Kruse AC. Crystal structure of the human $\sigma 1$ receptor. Nature 2016;532:527-30.

43 Tagashira H, Shinoda Y, Shioda N, Fukunaga K. Methyl pyruvate rescues mitochondrial damage caused by SIGMAR1 mutation related to amyotrophic lateral sclerosis. Biochim Biophys Acta 2014;1840:3320-34.

44 Wang L, Duncan G. Silencing of sigma-1 receptor induces cell death in human lens cells. Exp Cell Res 2006;312:1439-46.

45 Langa F, Codony X, Tovar V, Lavado A, Giménez E, Cozar P, Cantero M, Dordal A, Hernández E, Pérez R, Monroy X, Zamanillo D, Guitart X, Montoliu L. Generation and phenotypic analysis of sigma receptor type I (sigma 1) knockout mice. Eur J Neurosci 2003;18:2188-96

46 Bernard-Marissal N, Médard J-J, Azzedine H, Chrast R. Dysfunction in endoplasmic reticulum-mitochondria crosstalk underlies SIGMAR1 loss of function mediated motor neuron degeneration. Brain 2015;138:875-90 